\title{
Helicobacter pylori infection in patients with early gastric cancer by the endoscopic phenol red test
}

\author{
K Iseki, M Tatsuta, H Iishi, M Baba, S Ishiguro
}

\begin{abstract}
Background-An endoscopic procedure that uses a pH indicator called phenol red to assess Helicobacter pylori infected gastric mucosa has recently been developed. This test makes it possible to take biopsy specimens from $H$ pylori infected areas. Aim-This test was applied to patients with early gastric cancers to clarify the role of $\mathrm{H}$ pylori in gastric carcinogenesis. Subjects-Sixty five patients with early gastric cancer (50 with differentiated adenocarcinoma and 15 with undifferentiated adenocarcinoma).

Methods-Patients with early gastric cancer underwent the endoscopic phenol red test before their operation. In this test, areas infected with $H$ pylori can be observed as "coloured" areas where phenol red was turned from yellow to red.

Results-H pylori infection was significantly $(\mathrm{p}<0.001)$ more frequent in patients with differentiated adenocarcinomas than in those with undifferentiated adenocarcinomas. Differentiated adenocarcinomas were usually located in areas of mucosa infected with $H$ pylori, but undifferentiated adenocarcinomas were frequently located in non-infected areas.

Conclusion-H pylori may be a strong risk factor for differentiated early gastric cancer.

(Gut 1998;42:20-23)
\end{abstract}

Osaka Medical Centre for Cancer and Cardiovascular Diseases,

Osaka, Japan:

Department of

Gastroenterology

K Iseki

Department of Gastrointestinal Oncology

M Tatsuta

H Iishi

M Baba

Department of

Pathology

$S$ Ishiguro

Correspondence to:

Dr K Iseki,

Department of

Gastroenterology,

Osaka Medical Centre for

Cancer and Cardiovascular

Diseases,

3-3, Nakamichi 1-chome,

Higashinari-ku,

Osaka 537, Japan

Accepted for publication 7 August 1997
Keywords: endoscopic phenol red test; Helicobacter pylori; gastric cancer; differentiated adenocarcinoma; high risk factor

Evidence is rapidly accumulating that Helicobacter pylori is an important risk factor for human gastric adenocarcinoma..$^{1-5}$ It is still unsolved, however, as to which histological type of gastric cancer $H$ pylori infection is most closely related..$^{6-12}$ Previously, we found by culture of biopsy specimens that $H$ pylori may be a strong risk factor for the differentiated type of early gastric cancer. ${ }^{13}$ However, to discuss the relation between the presence of $H$ pylori and gastroduodenal disorders only on the basis of results from biopsy studies of fixed points in the human stomach is not sufficient, ${ }^{13}$ because the organism is not evenly distributed on the human gastric mucosa. ${ }^{14}{ }^{15}$ Recently, Kohli et al developed an endoscopic procedure that uses phenol red to observe areas infected with $H$ pylori. ${ }^{16-18}$ In the present study therefore we used this endoscopic test to investigate the prevalence of $H$ pylori infection and the location of cancers in relation to $H$ pylori infected areas in patients with early gastric cancer.

\section{Patients and methods}

From 1992 to 1995, the endoscopic phenol red test was done on 65 patients with early gastric cancer and 14 patients with gastric adenoma to investigate the prevalence of $H$ pylori infection and the location of early gastric cancers and adenomas in relation to gastric mucosa infected with $H$ pylori. ${ }^{19}$

Informed consent was obtained from all patients, and the study was carried out in accordance with the Declaration of Helsinki.

\section{ENDOSCOPIC PHENOL RED TEST}

The distribution of $H$ pylori in gastric mucosa was examined by the endoscopic phenol red test, developed by Kohli et al, details of which have been reported previously. ${ }^{16-18}$ Briefly, each patient was given $20 \mathrm{mg}$ of omeprazole (Omepral, Fujisawa Pharmaceutical Company Ltd, Osaka, Japan) orally at bedtime the day before the test or $20 \mathrm{mg}$ of famotidine (Gaster, Yamanouchi Pharmaceutical Company Ltd, Tokyo, Japan) intravenously 30 minutes before the test to reduce gastric acid secretion. Five minutes before endoscopy, $80 \mathrm{mg}$ of dimethylpolysiloxane (Gascon, Kissei Pharmaceutical Company Ltd, Matsumoto, Japan) was given orally to remove adherent gastric mucus and 20 $\mathrm{mg}$ of scopolamine butylbromide (Buscopan, Behringer Ingelheim Company Ltd, Kawasaki, Japan) was injected intramuscularly to reduce gastric motility. A videoendoscope was then inserted, gastric juice was aspirated to improve visibility during endoscopy, and the interior of the stomach was inspected. A spray tube was inserted through the biopsy forceps channel, and $0.1 \%$ phenol red solution with $5 \%$ urea was sprayed over the entire surface of the gastric mucosa. Changes in colour occurred within two to three minutes after the dye was sprayed and continued for at least 15 minutes. Areas where phenol red had turned from yellow to red owing to $H$ pylori infection were designated "coloured" areas, whereas areas where the colour had not changed were designated "non-coloured" areas.

The extent of $H$ pylori infected areas was classified on the basis of the extent of coloured areas as follows: (1) none: no areas in the stomach infected with $H$ pylori; (2) localised: $H$ pylori infected areas detected in parts of the stomach; and (3) diffuse: $H$ pylori infected areas detected from the antrum to the cardia. 
ASSESSMENT OF H PYLORI INFECTION

During the endoscopic phenol red test, three biopsy specimens were taken with a sterilised biopsy forceps (FB-25U, Olympus Optical Company Ltd, Tokyo, Japan) from coloured and non-coloured areas in the stomachs of all patients. After each examination, endoscopes were cleaned with detergent, disinfected with $10 \%$ ethanol, and rinsed with sterile water.

Two biopsy specimens taken from each area were homogenised in a microhomogeniser (Radnoti Glass Technology Company Ltd, Monrovia, CA, USA) with $100 \mu \mathrm{l}$ sterile saline and inoculated onto the surface of Brucella agar plates with $7 \%$ defibrinated horse blood and helicobacter selective supplement (Skirrow, Oxoid Company Ltd, Basingstoke, UK). Inoculation was performed within two to three hours of sampling. Agar plates were incubated for four days under $10 \% \mathrm{CO}_{2}$ in air. Specimens were considered positive for $\mathrm{H}$ pylori if one or more colonies of curved or spiral shaped, Gram negative bacteria were found which were positive for oxidase, catalase, and urease. In such cases, one colony was cultured and identified by these characteristics: no hydrolysis of hippurate; no growth in medium with $1 \%$ glycine, $1.5 \%$ sodium chloride, and $8 \%$ glucose; sensitivity to cephlethin ( $30 \mu \mathrm{g} /$ disk); resistance to nalidixic acid ( $30 \mu \mathrm{g} /$ disk); and growth in medium with $0.04 \%$ tetrazolium chloride. The bacteriologists who carried out the examinations were unaware of the endoscopic findings or grouping of specimens.

The third specimen, which was used for histological examination, was fixed in $10 \%$ formalin and processed in a routine manner. Sections were cut at 5 to $7 \mu \mathrm{m}$ and stained with Giemsa to show $H$ pylori organisms. Patients were considered not to have $H$ pylori infection when the culture was negative, when no $H$ pylori was seen on histological examination, and when no areas coloured with phenol red were detected on chromoendoscopy.

HISTOLOGICAL TYPE OF EARLY GASTRIC CANCERS The depths of involvement and the histological types of gastric cancer were determined histologically in specimens obtained at gastrectomy. Gastrectomy was performed two to 24 days (average duration: 12.5 days) after the phenol red test. Early gastric cancers were defined as those confined to the mucosa or submucosa with no involvement of the muscularis propria. ${ }^{20}$

According to the criteria of the Japanese Research Society for Gastric Cancer, early gastric cancers were histologically classified as follows: (1) well differentiated adenocarcinoma,

Table 1 Helicobacter pylori status in biopsy specimens obtained from coloured and non-coloured areas

\begin{tabular}{llcl}
\hline & \multicolumn{4}{l}{ Helicobacter pylori } & \\
\cline { 2 - 4 } & Positive & Negative & Total (\%) \\
\hline Coloured areas & $60(95) \dagger$ & $3(5)$ & $63(100)$ \\
Non-coloured areas & $5(8)$ & $60(92)$ & $65(100)$ \\
\hline
\end{tabular}

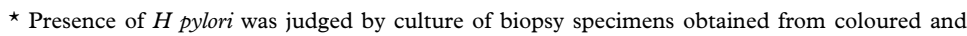
non-coloured areas.

+ Significantly different from the value for non-coloured areas at $\mathrm{p}<0.0001$.
(2) moderately differentiated adenocarcinoma, (3) poorly differentiated adenocarcinoma, and (4) signet ring cell carcinoma. ${ }^{19}$ The histological classification was based on the predominant pattern of the tumours. Well differentiated and moderately differentiated adenocarcinomas were defined as differentiated adenocarcinomas, and poorly differentiated adenocarcinomas and signet ring cell carcinomas as undifferentiated adenocarcinomas. In this series, mucinous adenocarcinomas and special type of cancers (for example, adenosquamous carcinoma and squamous cell carcinoma) were not found.

HISTOLOGICAL OBSERVATION OF SPECIMENS BY GASTRECTOMY

The location of early gastric cancers in relation to the extent of intestinal metaplasia and gastric mucosa infected with $H$ pylori was examined histologically in 25 specimens obtained at gastrectomy. All patients underwent the phenol red test before surgery.

After the operation, the stomach was opened, pinned flat on a cork mat, and fixed with $10 \%$ formalin solution. The fixed stomach was cut into longitudinal strips of $5 \mathrm{~mm}$ in width. The specimens were embedded in paraffin wax, and serial sections $5 \mu \mathrm{m}$ thick were stained with haematoxylin and eosin and immunohistochemically examined for the presence of $H$ pylori with anti-H pylori rabbit serum (Dako, Glostrup, Denmark). ${ }^{21}$

STATISTICAL ANALYSIS

Data were analysed by the $\chi^{2}$ test or Fisher's exact probability test. ${ }^{22}$ Significant indicates a calculated $\mathrm{p}$ value of less than 0.05 .

\section{Results}

H PYLORI IN BIOPSY SPECIMENS FROM COLOURED AND NON-COLOURED AREAS USING THE PHENOL RED TEST

Using the endoscopic phenol red test, $H$ pylori was detected in 60 (95\%) of 63 specimens obtained from coloured areas, but in only 5 ( $8 \%$ ) of 65 specimens obtained from noncoloured areas (table 1 ).

\section{H PYLORI INFECTION IN PATIENTS WITH EARLY} GASTRIC CANCERS AND ADENOMAS

With chromoendoscopy, H pylori infection was significantly more frequent in patients with differentiated adenocarcinomas than in those with undifferentiated adenocarcinomas (table 2). $H$ pylori infection was also significantly more frequent in patients with well differentiated and moderately differentiated adenocarcinomas than in those with poorly differentiated adenocarcinomas and signet ring cell carcinomas. H pylori infection was also significantly more frequent in patients with gastric adenomas than in those with undifferentiated tumours. Differentiated adenocarcinomas were usually in areas of mucosa infected with $H$ pylori, but undifferentiated adenocarcinomas were frequently in uninfected areas (table 3). 
Table 2 Helicobacter pylori infection in patients with adenoma and early gastric cancer in relation to the histological type of the cancer

\begin{tabular}{llllr}
\hline & \multicolumn{4}{l}{ Area infected with H pylori (\%) } \\
\cline { 2 - 5 } Histological type of gastric tumours & Diffuse & Localised & None & Total (\%) \\
\hline Differentiated adenocarcinoma & $42(84)^{\star}$ & $8(16)$ & $0(0)$ & $50(100)$ \\
$\quad$ Well differentiated type & $26(87) \dagger \ddagger$ & $4(13)$ & $0(0)$ & $30(100)$ \\
Moderately differentiated type & $16(80)$ S๙ & $4(20)$ & $0(0)$ & $20(100)$ \\
Undifferentiated adenocarcinoma & $2(13)$ & $7(47)$ & $6(40)$ & $15(100)$ \\
Poorly differentiated type & $1(20)$ & $2(40)$ & $2(40)$ & $5(100)$ \\
Signet ring cell carcinoma & $1(10)$ & $5(50)$ & $4(40)$ & $10(100)$ \\
Adenoma & $13(93)^{\star \star}$ & $1(7)$ & $0(0)$ & $14(100)$ \\
\hline
\end{tabular}

* Significantly different from the value for undifferentiated adenocarcinoma at $p<0.0001$.

$\dagger$ Significantly different from the value for poorly differentiated adenocarcinoma at $\mathrm{p}<0.01$.

$\ddagger$ Significantly different from the value for signet ring cell carcinoma at $\mathrm{p}<0.0001$.

$\$$ Significantly different from the value for poorly differentiated adenocarcinoma at $\mathrm{p}<0.05$.

- Significantly different from the value for signet ring cell carcinoma at $\mathrm{p}<0.01$.

$\star \star$ Significantly different from the value for undifferentiated adenocarcinoma at $\mathrm{p}<0.05$.

COLOURATION OF PHENOL RED IN RELATION TO INTESTINAL METAPLASIA

Intestinal metaplasia was significantly more frequent in differentiated adenocarcinomas than in undifferentiated adenocarcinomas (table 4). Five differentiated adenocarcinomas (38\%) were completely surrounded by intestinal metaplasia. Endoscopically these tumours were all located in the non-coloured areas far from the coloured area. This finding indicates that intestinal metaplasia did not affect the phenol red test.

\section{Discussion}

H pylori has strong urease activity and produces abundant quantities of ammonia on the surface of the gastric mucosa. ${ }^{23}$ Therefore, an endoscopic procedure using phenol red, a $\mathrm{pH}$ indicator, and urea to assess the distribution of $H$ pylori on human gastric mucosa has been developed by Kohli et al. ${ }^{16-18}$ This test has made it possible to obtain biopsy specimens accurately from areas infected with $H$ pylori. The prevalence of $H$ pylor $i$ infection in patients with differentiated adenocarcinoma increased therefore from $79 \%$ in our previous study, in which biopsy specimens were taken from the antrum, to $84 \%$ in the present study. ${ }^{13}$ Furthermore, using this test, we found that differentiated gastric cancers were significantly more frequently located in the areas infected with $H$ pylori than undifferentiated cancers were. These findings suggest that $H$ pylori may be closely related to the development of differentiated gastric cancers.

Data on the association of $H$ pylor $i$ with gastric cancer by histological type have been contradictory. ${ }^{24}$ When detection of $H$ pylori has been based on histological methods, the prevalence has generally been lower in the undifferentiated adenocarcinomas than in the differentiated adenocarcinomas. This difference has been less clear, or non-existent, in serological studies. This study, together with a previous one, shows that $H$ pylori infection may be a risk factor for differentiated early gastric cancers. ${ }^{13}$ Biopsy examination, however, can only detect current infection. It is also possible that by the time the undifferentiated process has taken place, the tissue is no longer receptive to $H$ pylori and this therefore does not exclude an aetiological linkage.

Many investigators have believed that $H$ pylori is not encountered in areas of intestinal metaplasia. ${ }^{25}$ Human secretory immunoglobulin A may be closely related to non-adherence of $H$ pylori to areas of intestinal metaplasia. ${ }^{26} 27$ Recently, however, Genta et al reported adherence of $H$ pylori to areas of incomplete intestinal metaplasia. ${ }^{25}$ In the present work, we found that $38 \%$ of differentiated adenocarcinomas were histologically surrounded by complete intestinal metaplasia and these tumours were all located in the non-coloured areas far from the area coloured by the phenol red test. These findings suggest that $H$ pylori does not adhere to the areas of complete intestinal metaplasia. The relation between incomplete intestinal metaplasia and adherence of $H$ pylori is still unknown.

The epidemiological relation between $H$ pylori and gastric cancer is widely accepted. However, the sequence of events leading to the development of carcinoma is unknown. A currently accepted model is that chronic active gastritis progresses to atrophic gastritis with intestinal metaplasia, to dysplasia, and, eventually, to neoplasia. ${ }^{28}$ The exact mechanism of this progression is still unclear however. Recent studies indicate that ammonia is involved in the development of gastric cancers that are

Table 3 Location of early gastric cancers in relation to Helicobacter pylori infected areas

\begin{tabular}{|c|c|c|c|c|}
\hline \multirow[b]{2}{*}{$\begin{array}{l}\text { Histological type of early } \\
\text { gastric cancer }\end{array}$} & \multicolumn{4}{|c|}{ Location of early gastric cancer (\%) } \\
\hline & $\begin{array}{l}\text { In areas infected } \\
\text { with } H \text { pylori }\end{array}$ & $\begin{array}{l}\text { Adjacent to areas infected } \\
\text { with } H \text { pylori }\end{array}$ & $\begin{array}{l}\text { Far from areas infected } \\
\text { with } H \text { pylori }\end{array}$ & Total (\%) \\
\hline Differentiated & $44(88)^{\star}$ & $1(2)$ & $5(10)$ & $50(100)$ \\
\hline Undifferentiated & $1(11)$ & $6(67)$ & $2(22)$ & $9(100)$ \\
\hline Total (\%) & $45(76)$ & $7(12)$ & $7(12)$ & $59(100)$ \\
\hline
\end{tabular}

* Significantly different from the value for undifferentiated adenocarcinomas at $\mathrm{p}<0.0001$.

Table 4 Location of early gastric cancer in relation to intestinal metaplasia

\begin{tabular}{lllll}
\hline & \multicolumn{4}{l}{ Location of early gastric cancer (\%) } \\
\cline { 2 - 5 } $\begin{array}{l}\text { Histological type } \\
\text { of gastric cancer }\end{array}$ & $\begin{array}{l}\text { Surrounded by } \\
\text { intestinal metaplasia }\end{array}$ & $\begin{array}{l}\text { Adjacent to or far from } \\
\text { intestinal metaplasia }\end{array}$ & $\begin{array}{l}\text { No intestinal } \\
\text { metaplasia }\end{array}$ & Total (\%) \\
\hline Differentiated & $5(38)$ & $8(62)$ & $0(0)$ & $13(100)$ \\
Undifferentiated & $0(0)$ & $6(50)$ & $6(50)^{\star}$ & $12(100)$ \\
Total & $5(20)$ & $14(56)$ & $6(24)$ & $25(100)$ \\
\hline
\end{tabular}

^ Intestinal metaplasia was significantly $(\mathrm{p}<0.05)$ more frequent in differentiated than in undifferentiated adenocarcinomas. 
associated with $H$ pylori. ${ }^{29} 30$ Tsuji et al examined the role of ammonia on gastric carcinogenesis induced by $N$-methyl- $N$-nitro$N$-nitrosoguanidine in rats and found that rats treated with ammonia had a significantly higher incidence of gastric cancer. ${ }^{29}{ }^{30}$ Recently, however, we found that oral treatment with ammonium and sodium hypochlorite significantly increased the incidence of gastric cancers induced by $N$-methyl- $N$ '-nitro- $N$ nitrosoguanidine in rats. ${ }^{31}$ Hypochlorous acid reacts with ammonium to yield cytotoxic monochloramine, a powerful oxidising agent that reacts rapidly with target cell components. ${ }^{32}$ Our results suggest that gastric carcinogenesis related to $H$ pylori is mediated by monochloramine.

In conclusion, results of the present study suggest that $H$ pylori may be a strong risk factor for differentiated early gastric cancer.

1 Lee A. Helicobacter infection in laboratory animals: a model for gastric neoplasia? Ann Med 1995;27:575-82.

2 Forman D, Newell DG, Fullerton F, et al. Association between infection with Helicobacter pylori and risk of gastric cancer. BMF 1991;302:1302-5.

3 Parsonnet J, Friedman GD, Vandersteen DP, et al. Helicobacter pylori infection and risk of gastric carcinoma. $N$ Engl f Med 1991;325:1127-31.

4 Nomura A, Stemmermann GN, Chyou P, Kato I, Perez-Perez GI, Blaser MJ. Helicobacter pylori infection and gastric carcinoma among Japanese Americans in and gastric carcinoma among Japanes

5 Kikuchi S, Wada O, Nakajima T, et al. Serum antiHelicobacter pylori antibody and gastric carcinoma among Helicobacter pylori antibody and gastric

6 Endo S, Okuda T, Saito Y, Fujiki K, Okayasu I, Sato C. Detection of Helicobacter pylori infection in early stage gastric cancer. A comparison between intestinal- and diffuse-type gastric adenocarcinomas. Cancer 1995;75 2203-8.

7 Craanen ME, Blok P, Dekker W, Tytgat GN. Helicobacter pylori and early gastric cancer. Gut 1994;35:1372-4

$8 \mathrm{Hu}$ PJ, Mitchell HM, Li YY, Zhou MH, Hazell SL. Association of Helicobacter pylori with gastric cancer and observations on the detection of this bacterium in gastric cancer cases. Am 7 Gastroenterol 1994;89:1806-10.

9 Asaka M, Kimura T, Kato M, et al. Possible role of Helicobacter pylori infection in early gastric cancer development. Cancer 1994;73:2291-4.

10 Sasaki N. Helicobacter pylori and gastric cancer in view of relation to atrophy of background gastric mucosa. Nippon Rinsho 1993;51:3242-7.

11 Clarkson KS, West KP. Gastric cancer and Helicobacter pylori infection. F Clin Pathol 1993;46:997-9.

12 Buruk F, Berberoglu U, Pak I, Aksaz E, Celen O. Gastric cancer and Helicobacter pylori infection. Br f Surg 1993;80:378-9.
13 Tatsuta M, Iishi H, Okuda S, Taniguchi H, Yokota Y. Helicobacter pylori as a risk factor of differentiated type early gastric cancer. Cancer 1992;72:1841-5.

14 Kohli Y, Itoh S, Kato T, Fujiki N. Chronic gastritis and Campylobacter pylori. Fournal of Kyoto Prefectural University of Medicine 1989;98:205-14.

15 Goodwin CS, Armstrong JA, Marshall BJ. Campylobacter pyloridis, gastritis, and peptic ulceration. I Clin Pathol 1986;39:53-65.

16 Kato T, Kohli Y, Itoh S, et al. Endoscopic visualization of the distribution of Helicobacter pylori in the human gastric mucosa. Dig Endosc 1990;2:1485-91.

17 Kohli Y, Kato T, Itoh S, Iwaki M, Yamazaki Y, Hata M. Endoscopic diagnosis of Helicobacter pylori distribution on human gastric mucosa in vivo. Fournal of Kyoto Prefectural University of Medicine 1991;100:219-25.

18 Kohli Y, Kato T, Iwaki M, et al. The distribution of Helicobacter pylori in human gastric mucosa in vivo. Dig Endosc 1991;3:457-60.

19 Japanese Research Society for Gastric Cancer. Fapanese classification of gastric carcinoma. Tokyo: Kanehara, 1995.

20 Murakami T. Pathomorphogical diagnosis. In: Murakami T, ed. Gann monograph on cancer research. Tokyo: University of Tokyo Press, 1971:53-5.

21 Andersen LP, Holck S, Povlsen CO. Campylobacter pylori detected by indirect immunohistochemical technique. APMIS 1988;96:559-64.

22 Siegel S. Nonparametric statistics for the behavioural sciences. New York: McGraw Hill, 1956.

23 Kawano S, Tsuji M, Fusamoto H, Sato N, Kamada T Chronic effect of intragastric ammonia on gastric mucosal structures in rats. Dig Dis Sci 1991;36:33-8.

24 Martin-De-Argila C, Boixeda D, Redondo C, et al. Relation between histological subtypes and location of gastric cancer and Helicobacter pylori. Scand f Gastroenterol 1997;32: 303-7.

25 Genta RM, Gurer IE, Graham DY, et al. Adherence of Helicobacter pylori to areas of incomplete intestinal metaplasia in the gastric mucosa. Gastroenterology 1996;111:1206-11.

26 Sugiyama T, Furuyama S, Awakawa T, Kobayashi T, Yabana $\mathrm{T}$, Yauchi A. Local immune response in gastric mucosa to Helicobacter pylori infection with and without intestinal metaplasia. Eur f Gastroenterol Hepatol 1993; 5(suppl 1):S119-22.

27 Tsutsumi Y, Nagura H, Watanabe K. Immune aspects of intestinal metaplasia of the stomach; an immunohistochemical study. Virchows Arch 1984;403:345-59.

28 Genta RM. Helicobacter pylori as a promoter of intestinal metaplasia and gastric cancer: an alluring hypothesis in search of evidence. Eur $\mathcal{f}$ Gastroenterol Hepatol 1995; 7(suppl 1):S25-30.

29 Tsuji M, Kawano S, Tsuji S, et al. Ammonia: a possible promoter in Helicobacter pylori-related gastric carcinogenesis. Cancer Lett 1992;65:15-8.

30 Tsuji M, Kawano S, Tsuji S, et al. Mechanism for ammonia-induced promotion of gastric carcinogenesis in rats. Carcinogenesis 1995;16:536-6.

31 Iishi $\mathrm{H}$, Tatsuta $\mathrm{M}$, Baba $\mathrm{M}$, et al. Enhancement by monochloramine of the development of gastric cancers in rats: a possible mechanism of Helicobacter pylori-related gastric carcinogenesis. 7 Gastroenterol 1997;32:435-41.

32 Grisham MB, Hernandez LA, Granger DN. Xanthine oxidase and neutrophil infiltration in intestinal ischemia. Am f Physiol 1986;251:G567-74. 